\title{
Experimental Study and Numerical Simulation of Seismic Behavior for RC Columns Subjected to Freeze-Thaw Cycles
}

\author{
Qing Qin, Shansuo Zheng, Lei Li, Liguo Dong, Yixin Zhang, and Sha Ding \\ Department of Civil Engineering, Xian University of Architecture and Technology, Xian 710055, China \\ Correspondence should be addressed to Qing Qin; qinqingjd@163.com
}

Received 1 November 2016; Accepted 17 January 2017; Published 7 March 2017

Academic Editor: Yao Luan

Copyright (C) 2017 Qing Qin et al. This is an open access article distributed under the Creative Commons Attribution License, which permits unrestricted use, distribution, and reproduction in any medium, provided the original work is properly cited.

\begin{abstract}
Freeze-thaw of concrete is significantly responsible for serious damage to RC buildings, which may result in premature failure with little warning. Therefore, it is necessary to consider the effects of freeze-thaw environment when assessing seismic performance for RC structures. In this study, pseudo-static experiments of four RC columns were conducted in terms of different number of freezethaw cycles (FTCs). The results showed that the FTCs had an influence on the bearing capacity, ductility, strength, and stiffness of $\mathrm{RC}$ columns. What is more, the simulation results were commonly smaller than the experimental ones when simply assuming that the degrees of freeze-thaw damage for RC components were uniform. Thus, a numerical model considering uneven distribution of freeze-thaw damage was proposed by utilizing the results of Petersen's test for relative dynamic modulus of elasticity (RDME) for different depths of concrete sample and based on Berto's method which was proved to be effective to convert the numbers of FTCs under different freeze-thaw conditions. On the basis of the existing constitutive relations for concrete, four RC columns subjected to different numbers of FTCs were simulated by OpenSees. As a result, the simulation hysteretic curves were in good agreement with the experimental ones.
\end{abstract}

\section{Introduction}

In cold region, concrete material may be damaged because of freeze-thaw penetration [1]. The concrete material property and bond-slip between concrete and steel bar can be affected greatly by freeze-thaw cycles, and this kind of damage will be increased with the increase of the numbers of freezethaw cycles (FTCs) [1-3]. For lifecycle structural engineering, it is important to know the effect of freeze-thaw cycles on materials and structures. However, most of the relevant researches are mainly focused on the effect on concrete material and bond behavior; very scarce literature on the effect on structural level can be seen.

For the past few years, the experimental study on the material and bond behavior of frost-damaged concrete had more achievements. Hasan et al. (2004) [4] proposed a stressstrain model for concrete damaged by freezing and thawing based on plasticity and fracture of concrete elements which was empirically formulated as a function of plastic tensile strain from experimental data. Shang and Song (2006) [5] tested the biaxial compressive strength of the plain concrete cubes subjected to freeze-thaw. Petersen et al. (2007) [2] studied the freeze-thaw effects on concrete elastic modules and interfacial bond behavior and proposed a bond-slip model using relative dynamic elastic modules of concrete as damage variable. In Petersen et al's study, the distribution of the internal damage of concrete was tested. The results showed that the damage distribution is uneven. More recently, Duan et al. (2011) [1] studied the freeze-thaw effects on the stressstrain relationship for plain concrete and confined concrete. In Duan et al's study, the number of freeze-thaw cycles and the concrete strength were changed; then a general constitutive model was proposed but the damage of the concrete was assumed to be uniformly distributed. Several types of tests were conducted on frost-damaged concrete by Hanjari et al. (2011) [3]. As a result, the compressive strength, tensile strength, fracture energy, the tensile-crack opening relationship, bond strength, and slip value for frozen-thawed damaged concrete were measured.

While previous research has been primarily concerned with the frozen-thawed deterioration of material and bond properties, relatively little attention has been given to 
TABLE 1: The design parameters of specimens.

\begin{tabular}{lccccccc}
\hline $\begin{array}{l}\text { Specimen } \\
\text { number }\end{array}$ & Concrete strength grade & $\lambda$ & $n$ & $N(\mathrm{kN})$ & $\rho(\%)$ & $\rho_{v}(\%)$ & $\begin{array}{c}\text { Freeze-thaw } \\
\text { cycles }\end{array}$ \\
\hline Z-C1 & C50 & 5 & 0.3 & 300.6 & 3.01 & 1.18 & 0 \\
Z-C2 & C50 & 5 & 0.3 & 300.6 & 3.01 & 1.18 & 100 \\
Z-C3 & C50 & 5 & 0.3 & 300.6 & 3.01 & 1.18 & 200 \\
Z-C4 & C50 & 5 & 0.3 & 300.6 & 3.01 & 1.18 & 300 \\
\hline
\end{tabular}

Note: $\lambda$ is the shear span ratio; $n$ is the axial load ratio with design; $N$ is the axial force; $\rho$ is the ratio of longitudinal reinforcements of columns; $\rho_{v}$ is the volume-stirrup ratio of columns.

assessing the load-carrying and seismic capacity of frostdamaged RC structural component. With the development of artificial climate simulation, to be simulating the freeze-thaw effects on a $1 / 2$ scaled structural components in laboratory has been become a reality. Xu et al. (2016) [6] investigated the seismic performance of RC columns subjected to freezethaw tests which were carried out in Climate Simulation Laboratory. Subsequently, Yang et al. (2016) [7] investigate the influence of FTCs on the seismic performance of squat RC shear wall specimens which were frozen and thawed in same way with $\mathrm{Xu}$ et al.s. Although these test results have shown that FTCs have significant effects on the seismic performances of RC structural components, how to consider the influence of the freeze-thaw effects in a numerical model could not be involved in these literatures. Ueda et al. (2009) [8] used a two-dimensional rigid body spring model which could consider the experimentally observed cracking and plastic deformation caused by frost damage. Hanjari et al. (2013) [9] introduced a methodology to predict the load-carrying capacity of frozen-thawed $\mathrm{RC}$ beams using nonlinear finite element analyses; the uneven distribution of frozen-thawed damage in the large beams was not considered, which leads to smaller prediction results compared with test. Hayashida et al. (2014) [10] performed nonlinear finite element analysis using distributed reinforcement and smeared cracking models to evaluate the structural properties of frozen-thawed RC beams; one case was assigned a compressive strength for every element based on ultrasonic propagation velocity results, leading to poor results because of the restriction of numerical models. Berto et al. $(2014,2015)$ [11-13] extended the coupled environmental-mechanical damage model to model the frozen-thawed damaged RC beams; the effect of FTCs on compressive and tensile strength was considered separately and a new relationship to properly evaluate the equivalent number of FTCs was proposed; this equivalent relationship made it possible to use the constitutive models of frost-damaged concrete with different experimental conditions and sample size in the numerical model of RC structures. Thus, the uneven distribution of frozenthawed damage in RC structures with different environment conditions should be considered in the numerical model as a further study.

In this paper, the authors mainly focused on the freezethaw effects on structural level. Both the experimental and numerical methods were employed. Cyclic loading tests for four $1 / 2$ scale RC columns subjected to different numbers of
FTCs were carried out. And then a new concrete constitutive model which considered the uneven distribution of frozenthawed damage was proposed based on Petersen's experimental data. At last, the available constitutive models of frostdamaged concrete and the model proposed in this paper were used in OpenSees, respectively, to simulate the behavior of RC columns experiencing different numbers of FTCs, and compared with the test results.

\section{Experimental Program}

2.1. General Information of the Experiment. In RC momentresisting frame structures under severe ground motions, the points of inflection in the columns are assumed to lie at their midpoints. Therefore, the segment between midpoint and beam-column joint is intercepted as a specimen. Considering the limitation of the dimensions of the environmental chamber used in this study, four $1 / 2$ scale RC columns with invariable axial load ratio were designed for FTCs tests based on the current Chinese code (GB 50011-2010) [14]. Axial and lateral loads were transferred to the columns through the top with $200 \mathrm{~mm}$ range which needed more stirrups. The bases are clamped to the laboratory strong floor. Figure 1 shows the plan views and important reinforcement details for the specimens. The values of the primary study variables are summarized in Table 1.

2.2. Timeline of the Test. The specimens were divided into columns and foundation blocks and were cast in sequence due to the limiting dimensions of Climate Simulation Laboratory. The columns were first cast and cured for 4 weeks in a natural environment and then placed in $15-20^{\circ} \mathrm{C}$ water for a week before being placed into the laboratory. The freeze-thaw testing process would last $4 \sim 12$ weeks according to the desired levels of frozen-thawed damage. When the setting cycles were finished, the column was recast with foundation block. After the foundation blocks were cured for 4 weeks, the low cyclic loading tests were carried out. The detailed timeline of total experiment was shown in Figure 2.

2.3. Material Properties. The mixing ratio for C50 concrete used in these specimens was $400 \mathrm{~kg} / \mathrm{m}^{3}$ of cement, $980 \mathrm{~kg} / \mathrm{m}^{3}$ of sand, $810 \mathrm{~kg} / \mathrm{m}^{3}$ of fine gravel, and $165 \mathrm{~kg} / \mathrm{m}^{3}$ of water. The real strength of concrete and reinforcement bars was determined via material property tests. Three standard cubic specimens of concrete were prepared and the average cubic 


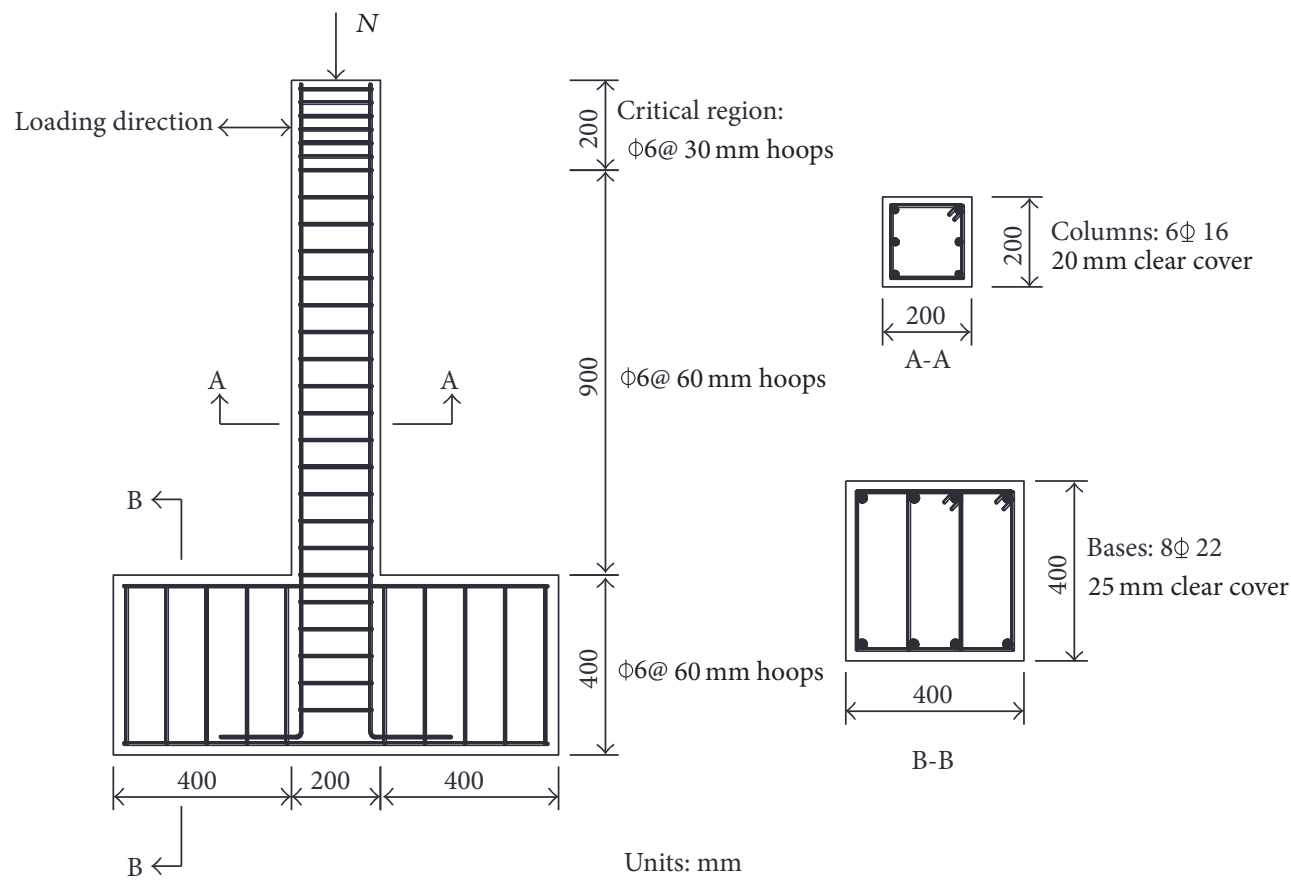

(a)

(b)

FIGURE 1: Column details including (a) specimen dimensions and (b) section details.

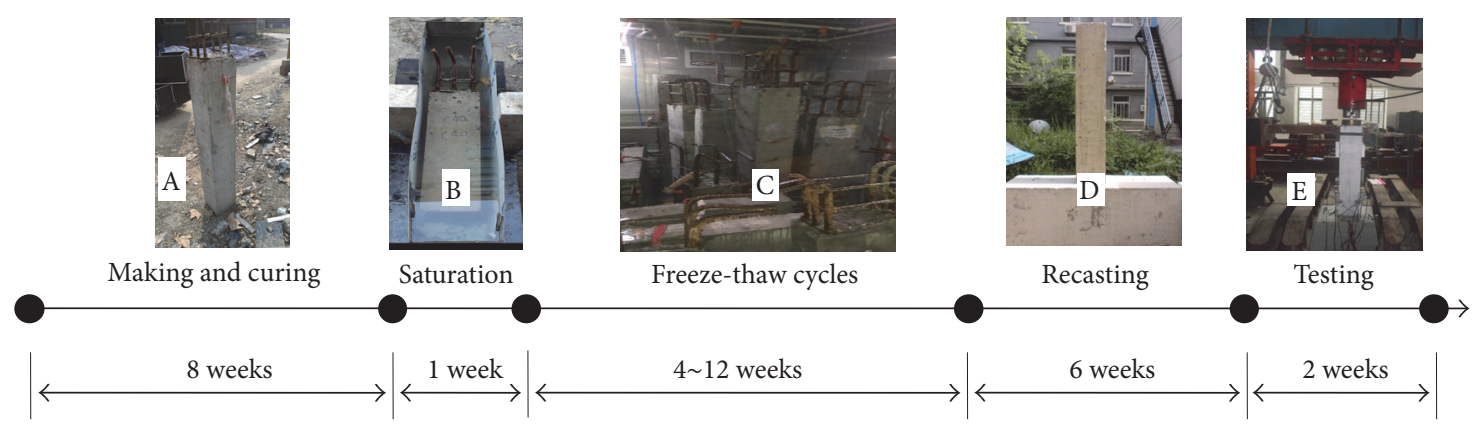

FIGURE 2: Timeline of the experiment.

TABLE 2: Mechanical properties of reinforcement bars.

Diameter Yielding strength Ultimate strength Elastic modulus

\begin{tabular}{lccc}
$(\mathrm{mm})$ & $f_{y}(\mathrm{MPa})$ & $f_{u}(\mathrm{MPa})$ & $E_{s}(\mathrm{MPa})$ \\
\hline$\$ 6$ & 270 & 470 & $2.1 \times 10^{5}$ \\
$\Phi 16$ & 373 & 537 & $2.0 \times 10^{5}$
\end{tabular}

compressive strength of the concrete was 55.08 MPa. Referring to [15], the axial compressive strength of concrete was 41.86 Mpa. Meanwhile, the longitudinal reinforcements for columns were Grade HRB335, and the stirrups were Grade HPB235. The properties of the reinforcement bars are shown in Table 2.

2.4. Details of Freeze-Thaw Cycles. The freeze-thaw tests for columns were carried out in Climate Simulation Laboratory as shown in Figure 2(C). The detailed design parameters of climate chamber could refer to the literature [7]. According to the Chinese code GB/T50082-2009 [16], the temperature setting of the freeze-thaw cycles was presented in Figure 3. To produce better freeze-thaw effects, 5 spray cycles were applied before each cycle began; each spraying cycle lasted for 3 minutes (one minute of spraying, followed by two minutes without spraying). Each freeze-thaw cycle lasted 5.5 hours, and 100 times FTCs would last 23 days. After 0 times, 100 times, 200 times, and 300 times FTCs, the compressive strength of concrete cylinders which were drilled out in walls was 53.73 Mpa, 49.64 Mpa, 44.25 Mpa, and 28.86 Mpa [7]. The columns and the walls belonged to the same batch FTCs tests.

2.5. Loading Scheme. After the foundation blocks were cured for 4 weeks, the low cyclic loading tests were carried out. The test devices are shown in Figure 4. Firstly, the target 


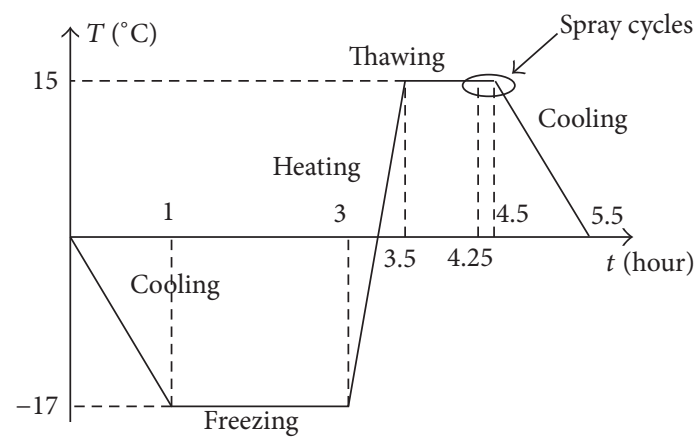

FIGURE 3: Details of temperature change in each cycle.

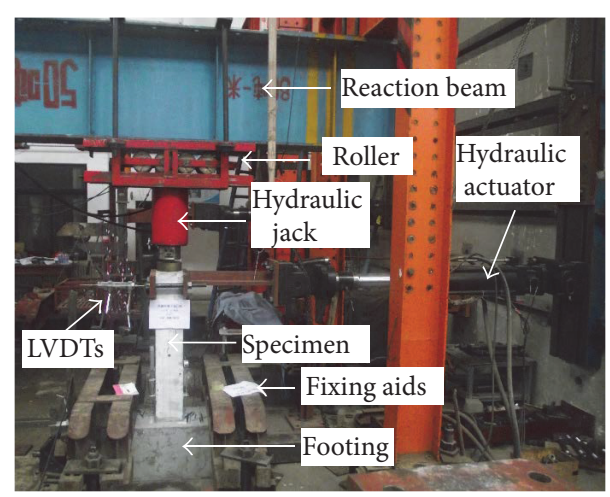

Figure 4: Loading system.

vertical load $300.6 \mathrm{kN}$ was exerted on the specimens via hydraulic jack, and the axial load ratio with experiment was 0.183 . Then, the actuator attached to the top of the specimen through the lateral load transfer assembly applied a lateral load; the vertical load was held constant throughout the testing process. Figure 5 illustrates the loading history of columns. Prior to the yielding of the specimen, the lateral load mode was exerted by the force-controlled load transfer assembly, increasing by an incremental load of $\pm 5 \mathrm{kN}$. After the yielding of the specimen, three cycles of loading and unloading were conducted for each subsequent displacement level, which increased by multiples of the yield displacement. When the bearing capacity of columns dropped to 85 percent of the peak load, loading ended. The lateral displacements of columns at the loading point were measured by horizontal LVDTs with $100 \mathrm{~mm}$ range, and the horizontal load was documented by a pull-pressure sensor.

\section{Experimental Results}

3.1. Cracks after Freeze-Thaw Cycles. After different freezethaw cycles, the characteristics of specimens' surface are shown in Figure 6. It is observed that some tiny cracks appeared on the surface of Z-C2 which was subjected to 100 times FTCs, as shown in Figure 6(a). When the number of FTCs increased, the number of cracks present increased and began to widen and extend. What is more, as the number

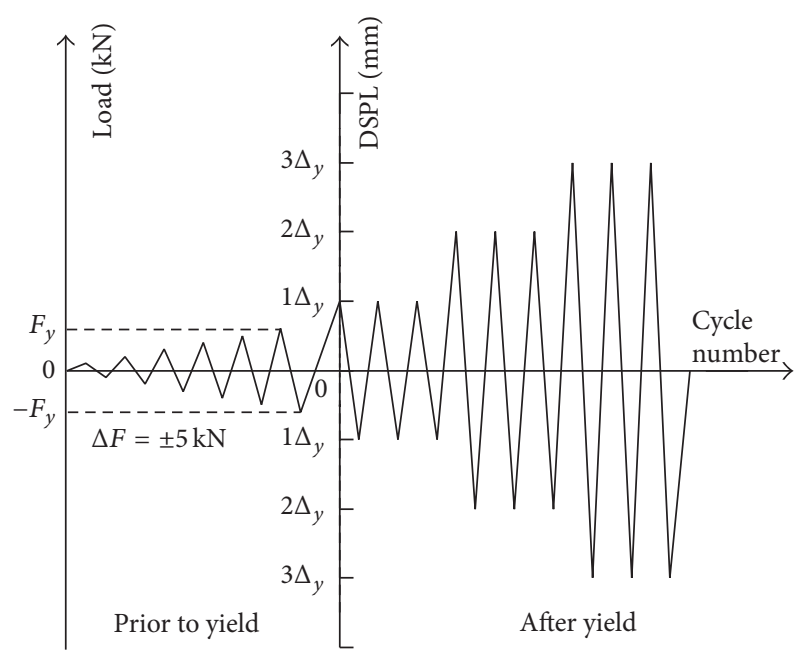

FIgURE 5: Loading protocol.

of FTCs increased to 300, the surface was no longer smooth and had "rise sand" phenomenon, as shown in Figure 6(c). Compared with the surface of frozen-thawed prism concrete specimens tested in literatures $[1,2]$, the freezing-thawing damage of columns was relatively light. One reason is because the specimens were drier in the climate chamber than when experiencing traditional frozen-thawed method with water. As a result, the ice inside concrete was less so that the stress was not large enough to spall the unconfined concrete which was similar to the real freeze-thaw environment. On the other hand, the size of cross section of columns is larger so that the uneven distribution of frozen-thawed damage in RC columns is more outstanding.

3.2. Failure Mode. Figure 7 illustrates the failure mode of columns. It can be seen that FTCs did not change the destruction form of RC columns where the shear span ratio was equal to 5. All specimens experienced typically bending-shear failures mainly dominated by flexure. Firstly, the flexural horizontal cracks were found at the bottom of the columns that ranged within $50 \mathrm{~mm} \sim 100 \mathrm{~mm}$. Subsequently, with the lateral load increased, the longitudinal reinforcements yielded; thus the horizontal cracks developed obliquely and some new inclined cracks emerged. Meanwhile, some vertical cracks appeared on the side perpendicular to the load direction at the bottom of columns. And then the concrete cover at the footing of columns began to spall. Furthermore, when the specimens were continued to load, the stirrups yielded and the longitudinal reinforcements were buckling, and the core concrete was crushed in large area so that the columns lost bearing capacity. After freeze-thaw cycles, the longitudinal reinforcements yielded early and the concrete at the footing of columns was crushed prematurely due to the fact that the strength of frozen-thawed concrete decreased gradually. The massive crushed concrete was transformed into granule depending on the degree of freezing-thawing damage, as shown in Figures $7(\mathrm{~b}) \sim 7(\mathrm{~d})$. In addition, the degree of granulation reduced gradually from the outer to 


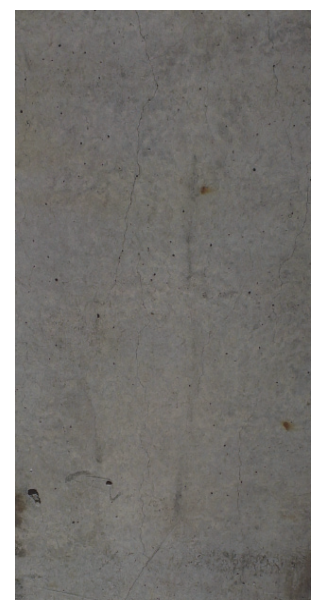

(a) 100 cycles

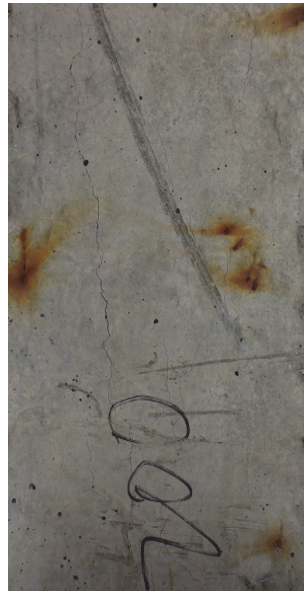

(b) 200 cycles

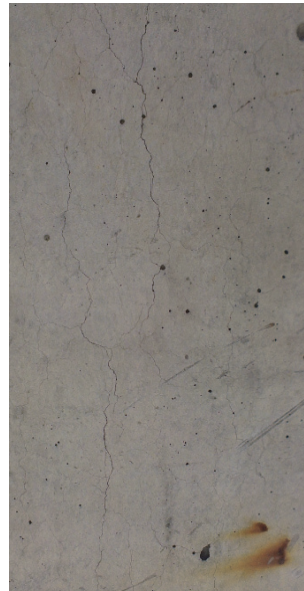

(c) 300 cycles

Figure 6: Columns surface after freeze-thaw cycles.

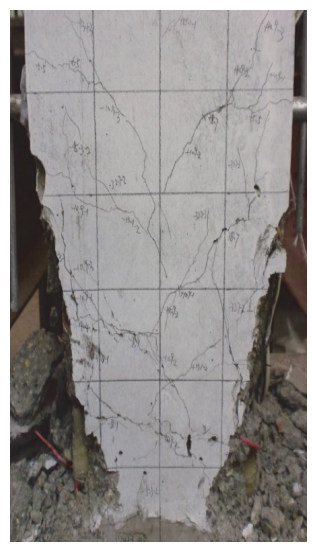

(a) 0 cycles

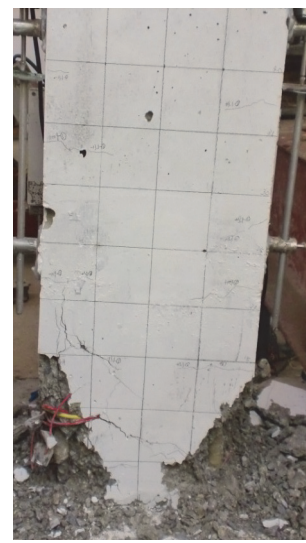

(b) 100 cycles

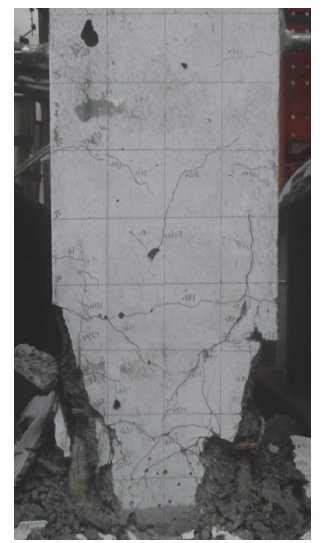

(c) 200 cycles

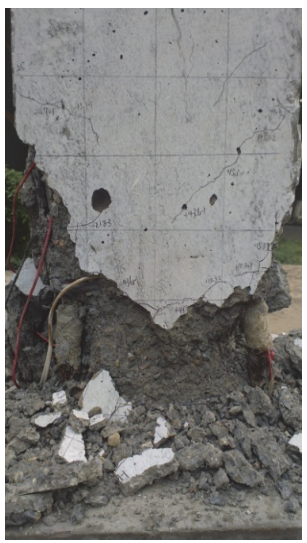

(d) 300 cycles

FIgURE 7: Failure mode of the columns.

the inner part of columns, which illustrated the uneven distribution of freezing-thawing damage.

\subsection{Experiment Results}

3.3.1. Hysteresis Behavior. The hysteretic curves of the lateral load versus the top displacement for the four specimens are shown in Figure 8. All specimens were destroyed with typical bending-shear failures; the hysteretic characteristics of specimens subjected to different number of FTCs are similar; that is, the intact specimen Z-C1 without FTCs was taken as an example to describe the failure process. At the initiation of loading, the specimen had yet to yield and was in elastic stage, and the curves of loading and unloading were keep in a straight line approximately. When the specimen yielded, the specimen began to access elastic-plastic stage, the loading and unloading stiffness was reduced gradually, and the residual deformation for positive and negative loading direction increased with smaller amplitude prior to the peak state. After the specimen reached the peak, the loading and unloading stiffness decreased sequentially and the residual deformation increased with larger amplitude, and the degradation of strength and stiffness for hysteretic loops was not obvious at the same displacement level.

With the increase of freeze-thaw cycles, the bearing capacity of specimens decreased gradually; however the displacements for different damage states increased slightly, which mainly attributed these results to the decrease of strength and the increase of ductility for concrete material subjected to FTCs $[2,5]$. Prior to the peak, the loading and unloading stiffness had not diminished much compared with the intact specimen $\mathrm{Z}-\mathrm{Cl}$, and the residual deformation had a tendency to increase. After the peak state, not only did the degradation of stiffness become more serious and the residual deformation increase with larger amplitude, but also the degradation of strength and stiffness for hysteretic loops 


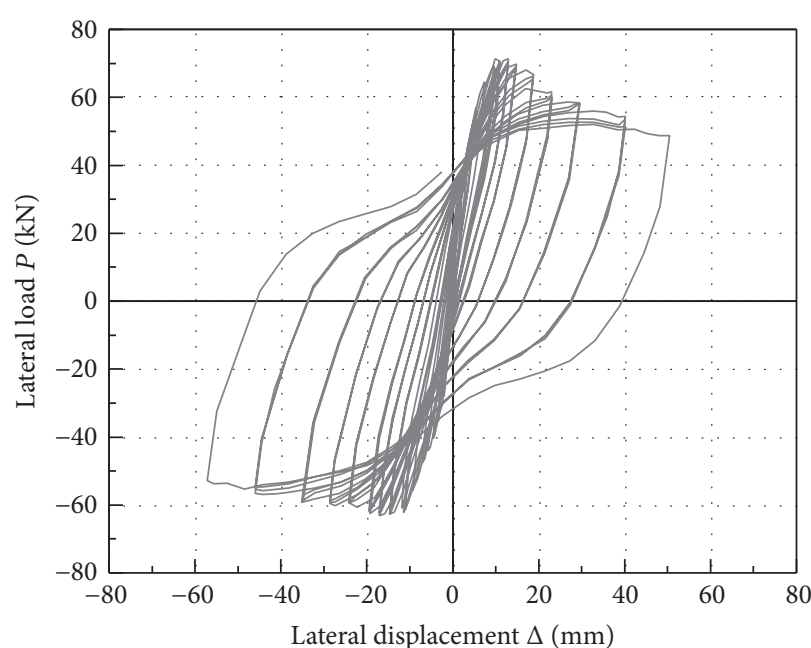

(a) Z-C1 (0 cycles)

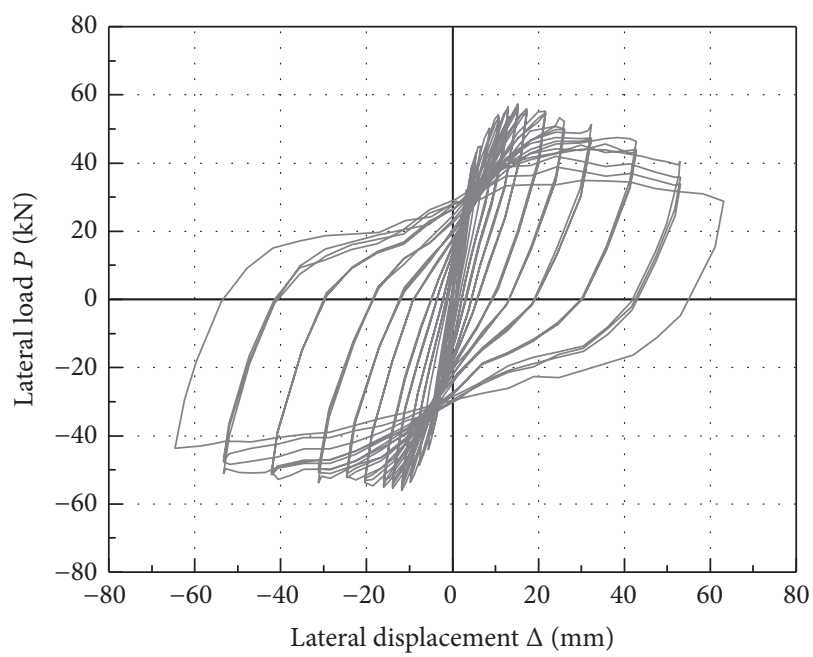

(c) Z-C3 $(200$ cycles)

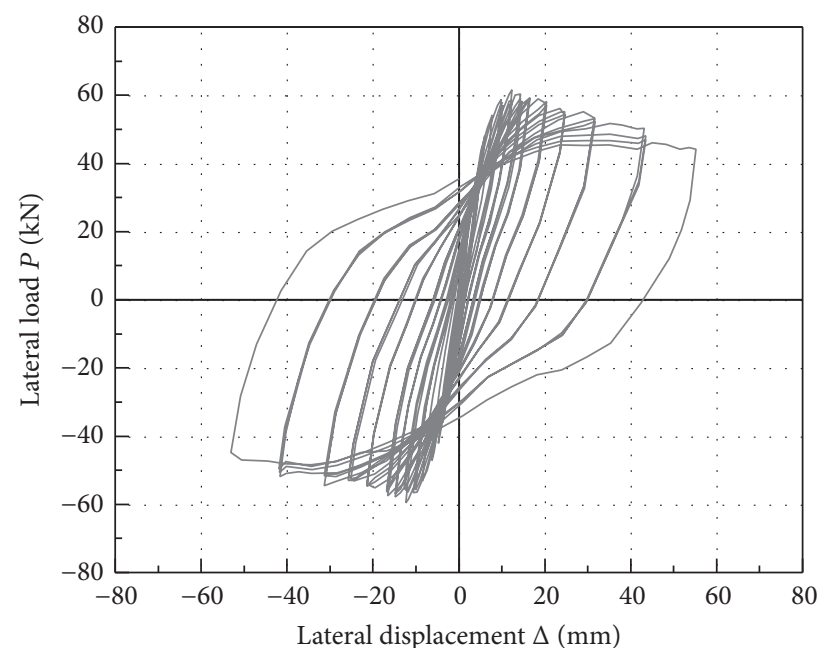

(b) Z-C2 (100 cycles)

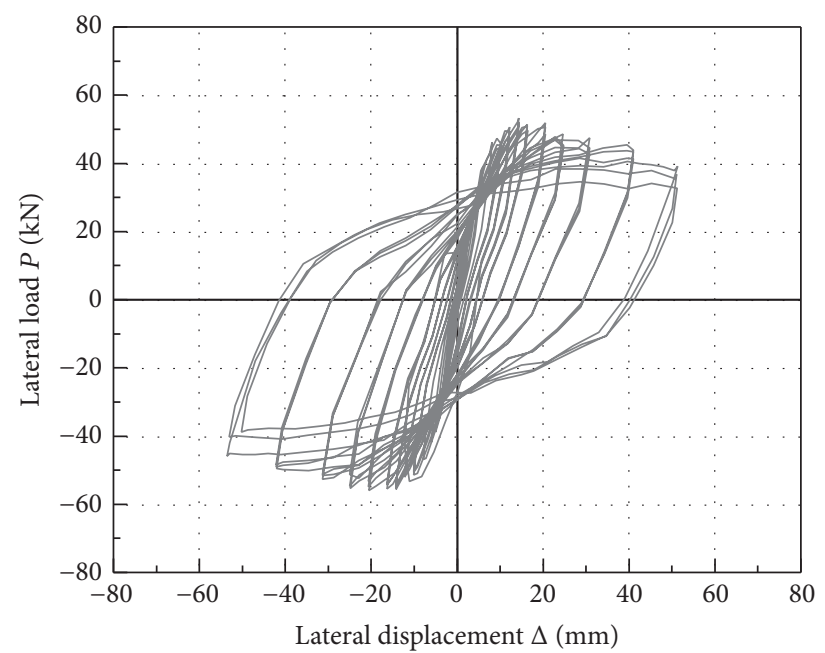

(d) Z-C4 (300 cycles)

FIGURE 8: Hysteric curves of columns.

was increasingly obvious at the same displacement level. The effect of the freeze-thaw cycles on the hysteretic behavior of the specimens is significant.

3.3.2. Characteristic Parameters of Skeleton Curves. Skeleton curves of the columns are plotted in Figure 9. Based on the equivalent elastoplastic energy absorption theory (recommended by Park [17]), the yield load and displacement were calculated. And then, the ultimate state was defined by the point on the descending branch with $85 \%$ of the maximum load. What is more, the ductility factor which reflects the deformation capacity of structures was expressed as the ratio of the ultimate displacement and the yield displacement [18]. Because the skeleton curves are asymmetric, the characteristic parameters are calculated as the average of absolute values of pull and push direction, which are presented in Table 3.
Based on Figure 9 and Table 3, some observations and regularity understandings are obtained as follows.

(1) Influence of FTCs on the Load-Carrying Capacity. Note that the yielding and peak load decreased as the number of FTCs increased. After 100 times, 200 times, and 300 times FTCs, the yielding load of frozen-thawed specimens compared with specimen Z-C1 has fallen by $9.72 \%, 14.90 \%$, and $15.70 \%$, respectively, and the correspondingly peak load has fallen by $9.44 \%, 15.62 \%$, and $18.68 \%$. These results indicated that the effect of the FTCs on the load-carrying capacity was significant.

(2) Influence of FTCs on the Deformation Capacity. According to the test researches of constitutive relations for freezingthawing concrete in literatures $[1,3,5]$, the compressive strength of concrete was decreased as the number of FTCs increased; however the ductility was increased mainly due 
TABLE 3: Force and deformation of the tested columns (unit: $\mathrm{mm} \& \mathrm{kN}$ ).

\begin{tabular}{lcccccccc}
\hline Specimen & Cycles & $F_{y}(\mathrm{kN})$ & $\Delta_{y}(\mathrm{~mm})$ & $F_{\max }(\mathrm{kN})$ & $\Delta_{\max }(\mathrm{mm})$ & $\begin{array}{c}F_{u}(\mathrm{kN}) \\
\left(0.85 F_{\max }\right)\end{array}$ & $\Delta_{u}(\mathrm{~mm})$ & $\Delta_{u} / \Delta_{y}$ \\
\hline Z-C1 & 0 & 55.99 & 7.26 & 66.92 & 14.42 & 56.88 & 38.45 \\
Z-C2 & 100 & 50.55 & 7.14 & 60.60 & 14.58 & 51.51 & 44.03 \\
Z-C3 & 200 & 47.65 & 7.40 & 56.47 & 14.6 & 48.00 & 44.48 \\
Z-C4 & 300 & 47.20 & 8.50 & 54.42 & 14.28 & 46.26 & 6.16 \\
\hline
\end{tabular}

Note: $F_{y}$ and $\Delta_{y}$ are the yield load and displacement; $F_{\max }$ and $\Delta_{\max }$ are the peak load and displacement; $F_{u}$ and $\Delta_{u}$ are the ultimate load and displacement; $\Delta_{u} / \Delta_{y}$ is the displacement ductility coefficient.

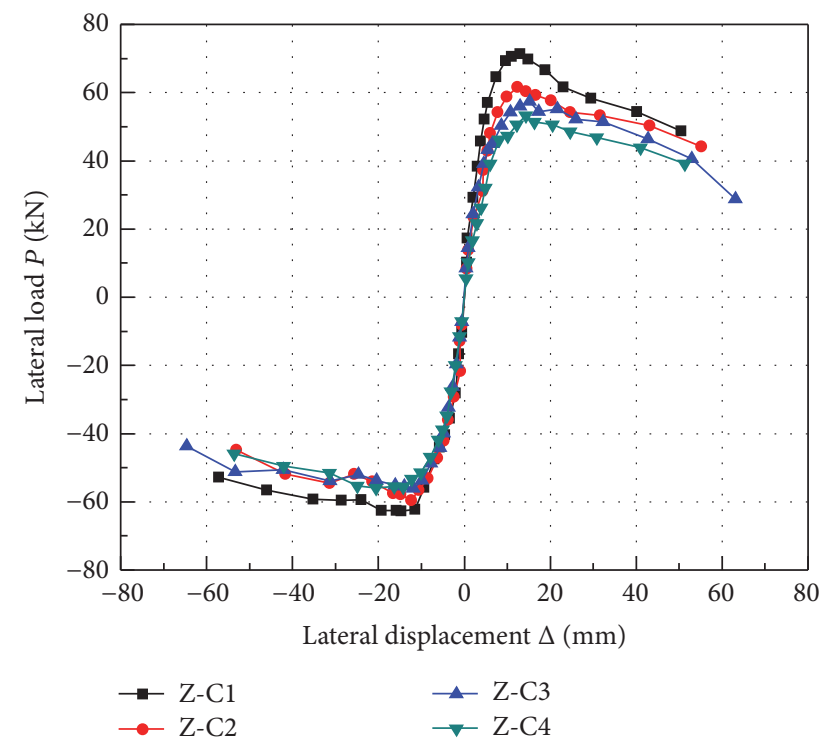

FIGURE 9: Experimental skeleton curves.

to the internal microcracks for concrete with different numbers of FTCs. As for the RC specimens designed in this paper, with the increases of the number of FTCs, the internal microcracks in concrete developed continuously, which resulted in the increasing trend for yielding displacement, peak displacement, and ultimate displacement. After 100 times, 200 times, and 300 times FTCs, the yielding displacement of frozen-thawed specimens compared with specimen $\mathrm{Z}-\mathrm{Cl}$ increased by $-1.65 \%, 1.93 \%$, and $17.08 \%$, the peak displacement increased by $1.11 \%, 1.25 \%$, and $-0.97 \%$, and the ultimate displacement increased by $14.51 \%, 15.68 \%$, and $10.9 \%$. Because the increases of ultimate displacement are less than the decreases of yield displacement, the ductility factors of freezing-thawing specimens declined, which is consistent with the test results in literature [6].

\section{Modeling of the Columns Subjected to Freeze-Thaw Cycles}

4.1. General Model. Generally, four element types were commonly used to simulate RC components, which were divided into force-based beam-column element (FB), displacementbased beam-column element (DB), solid finite element (SFE), and beam-column element with concentrated plastic hinges

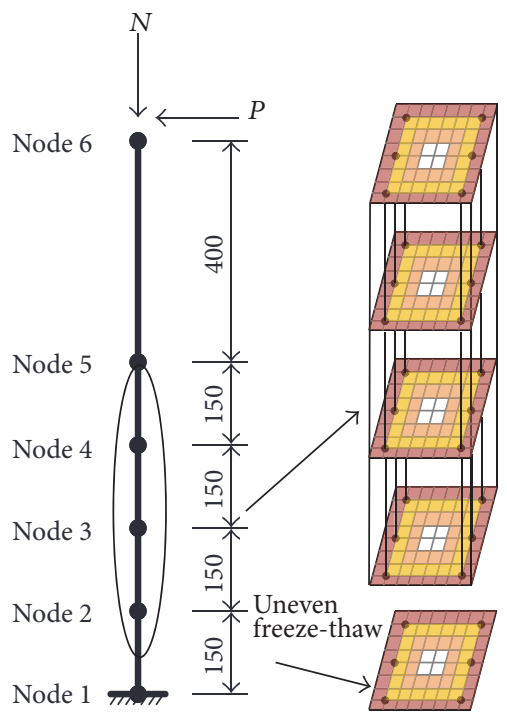

FIGURE 10: Analytical model of column subjected to FTCs.

$(\mathrm{CPH})$, respectively [19]. When the RC column was subjected to FTCs, the length of plastic hinge had been changing, as shown in Figure 7. Therefore, the displacement-based beam-column element which is based on the displacement formulation and considers the spread of plasticity along the element was used in this paper. In order to improve the accuracy of model prediction, the optimal number of elements for DB elements should be defined as [19].

When the RC column was modeled in OpenSees, firstly, five elements were divided into by six nodes along the vertical direction of column, because the elastic-plastic deformation was mainly focused on the bottom of RC column, which was divided into four elements with $150 \mathrm{~mm}$. In addition, the top of RC column tended to be more flexible, which was divided into one element with $400 \mathrm{~mm}$. What is more, the footing was assumed to be stiff end, and Node 1 was fixed. And the illustration of analytical model was shown in the left-hand side of Figure 10. Secondly, the number of Gauss integration points of the displacement-based beam-column element was 5. Fiber section model was used to define the element, and the rectangular section was dispatched by 40 fibers $\times 40$ fibers. Finally, each fiber should be defined as a Uniaxial Material which represents uniaxial stress-strain relationships for steel and concrete. As for the longitudinal reinforcement, the steel fiber constitutive law followed Menegotto and Pinto (1973) 
[20], combined with the isotropic hardening rules proposed by Filippou et al. (1983) [21]. Longitudinal rebar buckling was not considered in the analysis. According to the material test results, the yield strength and the elastic modules of the reinforcement bars are $363 \mathrm{MPa}$ and $128918 \mathrm{MPa}$. The strain harden ratio is $1.5 \%$. In allusion to the concrete fibers, concrete cover material was represented through Kent-Park model which followed the constitutive relationship modified by Hisham and Yassin (1994) [22]. And the compression envelope of confined concrete was calibrated using the empirical relations proposed by Mander et al. (1988) [23] for the peak stress and the strain. For unloading and reloading in compression, the Karsan-Jirsa (1969) [24] was used to determine the slope of the curve for confined concrete. In order to consider the ductility of postcrushing concrete, a descending branch was calibrated such that the post-peak slope of the present stress-strain relationship agreed with Roy and Sozen's model [25] for confined concrete after reaching the peak value.

Petersen et al. (2007) [2] pointed out that the damage of FTCs on RC components was uneven; with the depth of freezing and thawing increasing, the degree of internal damage expressed as relative dynamic modulus of elasticity reduced gradually; the damage of uneven distribution over the cross section was illustrated in the right-hand side of Figure 10. Hanjari et al. (2013) [9] modified the concrete constitutive relationship based on the related experimental results for frozen-thawed concrete, and the effect of bond-slip between longitudinal reinforcement and frozen-thawed concrete was considered; in addition, the load-carrying capacity of frozenthawed RC beams had been predicted using nonlinear finite element analyses. For smaller cross section of RC beams, the predicted curves of load-deformation were in good agreement with test results. Moreover, for larger cross section of RC beams, because the uneven distribution of frozenthawed damage in the large beams was not considered, the effect of freezing-thawing damage on concrete had been amplified, which leads to smaller prediction results compared with test. Therefore, a modified model had been proposed to consider the uneven distribution of freeze-thaw in view of the concrete constitutive relationship applied to the above process of modeling RC columns, which was referenced to the measurements for relative dynamic modulus of elasticity (RDME) at various distances from the exposed surface in literature [2], as described in Section 4.3.

4.2. The Equivalent Number of FTC, $N_{e q}$. When the freezingthawing tests for concrete specimens (prismoids, cylinders) were carried out, various freezing-thawing devices and test specifications were adopted in different literature $[1,3,5]$, which led to the inconsistent frozen-thawed deterioration conditions, for example, freezing-thawing velocity, moisture content, and sample size. As a result, the observed degree of frozen-thawed damage was varied for specimens subjected to the same FTCs in different literatures, and this limits the mutual verification and statistical analysis for test data in different literature. Berto et al. (2015) [13] used the equivalent number of FTCs $\left(N_{\text {eq }}\right)$ according to ASTM C666 [26] "procedure A" which led to the same strength reduction to consider the above different FTC conditions. The relation for evaluation of $N_{\text {eq }}$ was proposed:

$$
N_{\text {eq }}=\chi N^{\gamma}
$$

where $N$ was the actual number of FTCs, while $\chi$ and $\gamma$ were parameters depending on the experimental conditions. The actual number $N$ of FTCs in Duan et al. tests, Shang and Song tests, and Hanjari et al. tests had been, respectively, transformed into the equivalent number $N_{\mathrm{eq}}$ through (1) by Berto et al. (2015), and the proposed FTD model had been validated with better applicability. Therefore, the above transformational method was used to transform the actual number $N$ of FTCs in the above freeze-thaw tests for columns and Petersen's tests, and then the modified model considering uneven distribution of freeze-thaw was proposed to simulate the RC columns.

Petersen et al. (2007) [2] used the same specification with Hanjari et al. experimental tests (RILEM TC176-IDC [27]) to conduct freeze-thaw tests of concrete specimens. This standard was rather different than recommendations of ASTM C666 in terms of specimen dimension, freezingthawing rate, moisture content, and so on. Berto et al. (2015) investigated the influence of these experimental tests on the evaluation of $\chi$ and $\gamma$ based on a sensitivity analysis. The Ordinary Least Squares approach was used to obtain optimization parameters $(\chi=11.71$ and $\gamma=0.87)$ that best fit experimental results with small error based on observed RDME. The transformed $N_{\text {eq }}$ was written as

$$
N_{\text {eq }}=11.71\left(N_{\text {Hanjari }}\right)^{0.87} \text {. }
$$

Because Petersen et al.'s freezing-thawing tests were carried out on concrete samples immersed in water with one side, on the contrary, Hanjari's samples were immersed in water with all sides. When the sample reached the same degree of freeze-thaw damage, Petersen's test experienced more cycles than Hanjari's test. So we assumed that $N_{\text {Petersen }}=$ $\eta N_{\text {Hanjari }}$, where $\eta=2.5$.

As for the FTCs tests of RC columns mentioned above, the target temperatures were performed by GB/T50082-2009 [16], which is similar to the ASTM C666 proc. A. However, the freezing-thawing method described in Section 2.4 was different from the ASTM C666 because the specimens were not frozen-thawed in water; therefore a relatively lighter freeze-thaw condition was provided in this paper, and the section size of RC columns did not meet the standard requirements. For these reasons, the equivalent number $N_{\mathrm{eq}}$ of FTCs needed to be estimated. To this aim the parameters $\chi$ and $\gamma$ were estimated considering the degradation of strength experimentally observed on cylinder specimens drilled out from squat $\mathrm{RC}$ walls which belonged to the same batch FTCs tests in climate chamber. In order to consider the degradation of concrete compressive strength with the deterioration of environment, according to the literature [13], the environmental damage parameter may be written as

$$
d_{\mathrm{env}}=1-\frac{f_{c}^{d}}{f_{c}}
$$




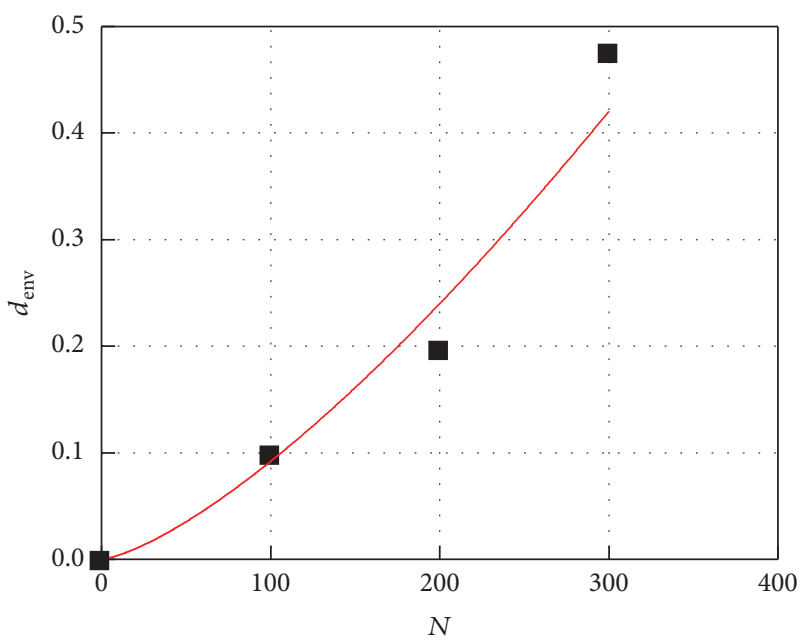

Exp. in this paper

Eq. (4)

FIGURE 11: Relation between $d_{\text {env }}$ and $N_{\text {exp. }}$.

where $f_{c}^{d}$ and $f_{c}$ are, respectively, the values of compressive peak stress in degraded and sound conditions. The corresponding values of $d_{\text {env }}$ for $0,100,200$, and 300 FTCs are plotted in Figure 11 with rectangular block and evaluated by regression analysis shown in Figure 11 with red line. The results of the regression analyses are summarized as follows:

$$
\begin{aligned}
d_{\text {env }} & =1.565 \times 10^{-4} N_{\text {exp. }}^{1.384}, \\
R^{2} & =0.87 .
\end{aligned}
$$

According to the literature [11], the frozen-thawed deterioration condition with ASTM C666 proc. A was considered, and the environmental damage parameter $d_{\text {env }}$ was calculated by

$$
d_{\mathrm{env}}=\left(0.0114-0.00022 f_{\mathrm{C}}\right) N_{\mathrm{eq}},
$$

where $f_{C}[\mathrm{MPa}]$ is the cylindrical compressive strength. In this paper, the compressive strength of cube concrete was $55.08 \mathrm{MPa}$, and the corresponding cylinder compressive strength was $43.49 \mathrm{MPa}$ calculated by [15]. In principle the degradation of concrete strength was the same under different freezing-thawing conditions; the actual number $N_{\text {exp. }}$ in the above FTCs tests about RC columns was transformed by

$$
N_{\text {eq }}=8.542 \times 10^{-2} N_{\text {exp. }}{ }^{1.384} .
$$

Based on (2) and (6), the corresponding numbers of FTCs with different frozen-thawed conditions were calculated as listed in Table 4.

4.3. Proposed Model. Petersen et al. (2007) [2] studied the effects of freezing-thawing depth on relative dynamic modulus of elasticity, the test results were shown in Figure 13 with labeled lines, and the internal damage was more pronounced and progresses into the specimen with an increasing number
TABLE 4: The corresponding numbers of FTC with different frozenthawed conditions.

\begin{tabular}{lcc}
\hline$N_{\text {exp. }}$ & $N_{\text {eq }}$ (ASTM C666 proc. A) & $N_{\text {Petersen }}$ (RILEM TC176-IDC) \\
\hline 100 & 50.07 & 13.27 \\
200 & 130.67 & 40.03 \\
300 & 229.03 & 76.25 \\
\hline
\end{tabular}

of FTCs. According to the characteristics of the labeled lines in Figure 13, we assumed that (1) the freezing-thawing environment around the specimens' surface was identical and the corresponding damage degree of freeze-thaw at the same distance was identical as well; (2) the relative dynamic modulus of elasticity (RDME) was held constant when the number of FTCs did not exceed the critical value $N_{i}^{\prime}$ where the corresponding freeze-thaw depth was equal to $x_{i}$; and (3) the RDME was decreased linearly when the number of FTCs exceeded its critical value $N_{i}^{\prime}$. In this paper, the calculation model of RDME considering the uneven freeze-thaw damage was proposed based on the above assumption, as follows:

$$
\operatorname{RDME}= \begin{cases}1, & \text { if } N \leq N_{i}^{\prime}, \\ 1-m_{i}\left(N-N_{i}^{\prime}\right) \geq 5 \%, & \text { if } N>N_{i}^{\prime},\end{cases}
$$

where $N$ was the actual number of FTCs taken from Table 4 in Petersen's condition; $N_{i}^{\prime}$ was the corresponding number of FTCs at the $x_{i}$ freeze-thaw depth when the RDME began to decline, known as the critical value mentioned above, as shown in Figure 13; and $m_{i}$ was the corresponding slope for the linear decline lines shown in Figure 13 at the $x_{i}$ freezethaw depth. As for the freeze-thaw depth $x_{i}$, it is the minimum distance from exposed surface with both directions to the frozen-thawed concrete fiber, as shown in Figure 12. Based on the observation from the distribution of the internal damage over the specimen tested by Petersen which was shown in Figure 13 with labeled lines, the critical value $N_{i}^{\prime}$ increased with the freeze-thaw depth deepening, and the corresponding slope $m_{i}$ of linear decline line decreased continuously. Therefore, the linear regression analysis was used to confirm $N_{i}^{\prime}$ and $m_{i}$ which were written as (8), respectively. The calculated results were shown in Figure 13 with dashed lines, which was in good agreement with the test results.

$$
\begin{aligned}
& N_{i}^{\prime}=0.9 x_{i}+3, \\
& m_{i}=\frac{\left(1.3-0.008 x_{i}\right)}{100} .
\end{aligned}
$$

According to the British Code of Practice for Structural Use of Concrete CP110: 1972 [28], the relationship between the dynamic modulus of elasticity of concrete $E_{\mathrm{dyn}}$ and its strength $f_{C}$ was written as

$$
E_{\text {dyn }}=22+2.8 \sqrt{f_{C}},
$$

where $E_{\text {dyn }}[\mathrm{GPa}]$ was the dynamic modulus of elasticity of concrete without FTC and $f_{C}[\mathrm{MPa}]$ was the corresponding cylindrical compressive strength which was equal 


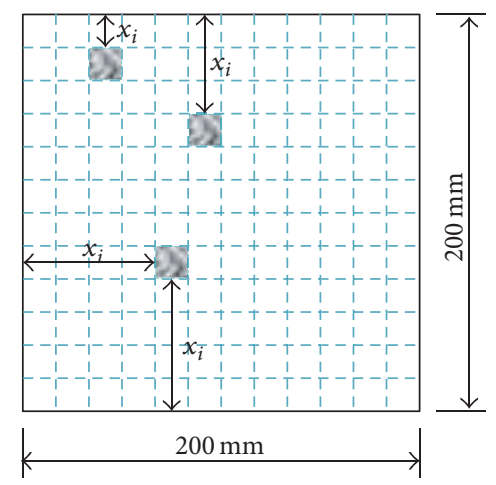

Frost concrete fiber location

FIGURE 12: The diagram for freeze-thaw depth $x_{i}$ with RC columns.

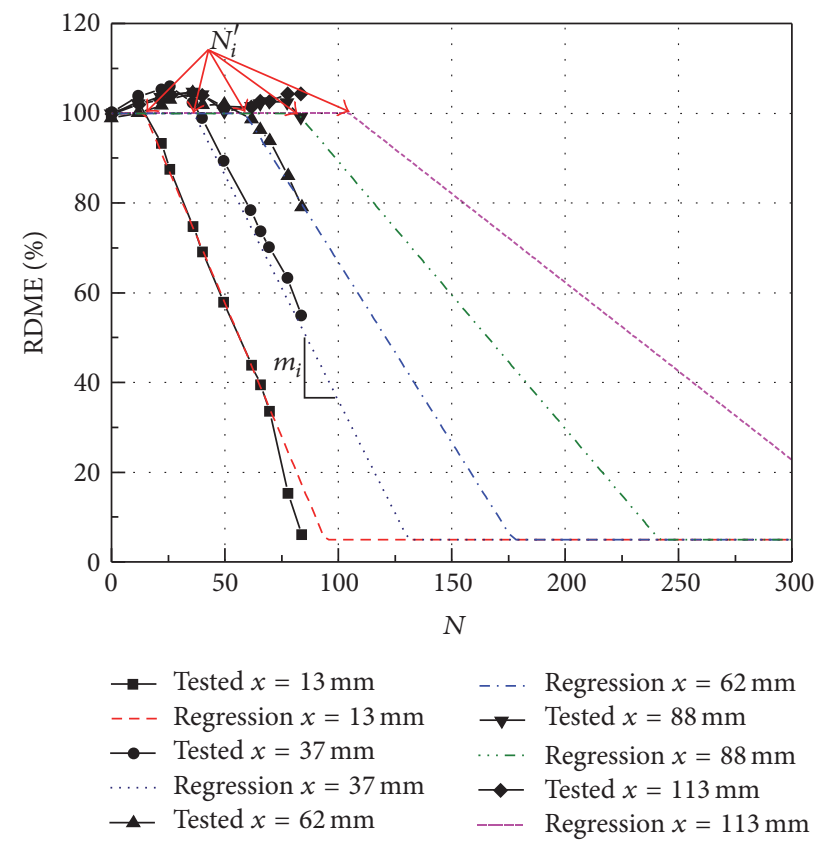

FIgURE 13: The comparison diagram between calculation and test results for RDME with various freeze-thaw depths.

to $43.49 \mathrm{MPa}$. Thus $E_{\text {dyn }}$ for undamaged concrete was $40.465 \mathrm{GPa}$ calculated by (9). According to (7) considering the uneven distribution of freeze-thaw damage, the damaged dynamic elastic modulus $E_{\mathrm{dyn}, i}^{d}[\mathrm{GPa}]$ for frozen-thawed concrete fiber with various freeze-thaw depth was written as follows:

$$
E_{\mathrm{dyn}, i}^{d}=\mathrm{RDME} \cdot E_{\mathrm{dyn}} .
$$

Hanjari et al. (2013) [9] had studied the regression analysis for relationships between the damaged dynamic elastic modulus and the cylindrical compressive strength for frozen-thawed concrete which were tested by Suzuki et al. (2007), Hanjari et al. (2009a), Fagerlund et al. (1994), and Shang et al. (2006). The compressive strength $f_{C, i}^{d}[\mathrm{MPa}]$ of frozen-thawed concrete fiber at various freeze-thaw depths was derived from Hanjari et al's (2013) regression model, as follows:

$$
f_{\mathrm{C}, i}^{d}=30.4 \cdot \sqrt[3 \cdot 3]{\frac{E_{\mathrm{dyn}, i}^{d}}{52.8-E_{\mathrm{dyn}, i}^{d}}}
$$

In allusion to the unconfined concrete subjected FTCs, the compressive strength of fiber at different freeze-thaw depth was directly calculated by (11). However, in view of confined concrete, the stirrup constraint coefficient $k_{i}$ for different frozen-thawed depth was introduced here to consider the confinement effect on freeze-thaw confined concrete. The compressive strength $f_{C C, i}^{d}$ [MPa] for confined concrete fiber at different freeze-thaw depth was calculated by

$$
f_{\mathrm{CC}, i}^{d}=k_{i} f_{C, i}^{d} \text {, }
$$

where $k_{i}$ was calculated for freeze-thaw concrete with different depth by Mander's method.

According to Petersen et al. [2] proposed equation derived from regression analysis of test results, the static modulus of elasticity $E_{c, i}^{d}[\mathrm{GPa}]$ for frozen-thawed concrete at different freeze-thaw depth was calculated by

$$
E_{c, i}^{d}=(0.9 \mathrm{RDME}-0.06) \times E_{c},
$$

where $E_{c}$ was the modulus of elasticity for undamaged concrete which was equal to $5000 \sqrt{f_{C}}$.

Based on the results calculated by (12) and (13), the compressive strength of frozen-thawed unconfined and confined concrete fiber and the corresponding static modulus of elasticity at different freeze-thaw depth were determined. The peak strain $\varepsilon_{0, i}$ for frozen-thawed unconfined concrete fiber was calculated by Kent-Park's constitutive relationship, as follows:

$$
\varepsilon_{0, i}=\frac{2 f_{C, i}}{E_{C, i}^{d}} .
$$

The peak strain $\varepsilon_{c 0, i}$ for frozen-thawed confined concrete fiber was calculated by Mander's constitutive relationship, as follows:

$$
\varepsilon_{c 0, i}=\varepsilon_{0, i} \times\left[1+5\left(k_{i}-1\right)\right] .
$$

The ultimate strain $\varepsilon_{c u, i}$ for frozen-thawed unconfined concrete fiber was easily taken as $2 \varepsilon_{0, i}$, and the ultimate strain $\varepsilon_{c c u, i}$ for frozen-thawed confined concrete was taken as 0.02 which is consistent with Mander's constitutive relationship. The input constitutive parameters for frozen-thawed concrete fibers with various freeze-thaw depths were calculated by looping statement in OpenSees script. At this point, the numerical model considering the uneven freeze-thaw for RC columns had been built. The bond-slip for steel bars was not taken into account in this paper, which needs to be thought about in future studies. 
TABLE 5: Input parameters of constitutive model for frozen-thawed unconfined concrete (Concrete02 in OpenSees).

\begin{tabular}{lcccccc}
\hline Specimen & Cycles & Depth $(\mathrm{mm})$ & $f_{C, i}^{d}(\mathrm{Mpa})$ & $\varepsilon_{0, i}$ & $\sigma_{c u, i}^{d}(\mathrm{Mpa})$ & 0 \\
\hline Z-C1 & 0 & $0-20$ & 43.57 & 0.0018 & 0.031 & 0 \\
Z-C2 & 100 & $0-10$ & 39.92 & 0.0031 & 0.0062 \\
& & $10-20$ & 43.57 & 0.0018 & 0 & 0.0036 \\
Z-C3 & 200 & $0-10$ & 28.69 & 0.0037 & 0 & 0.0074 \\
& & $10-20$ & 32.45 & 0.0033 & 0 & 0.0067 \\
Z-C4 & \multirow{2}{*}{300} & $0-10$ & 15.75 & 0.0158 & 0 & 0.0316 \\
& & $10-20$ & 20.94 & 0.0062 & 0.0124 \\
\hline
\end{tabular}

Note: $\sigma_{c u, i}^{d}$ is the ultimate stress of frozen-thawed concrete.

TABLE 6: Input parameters of constitutive model for frozen-thawed confined concrete (Concrete04 in OpenSees).

\begin{tabular}{|c|c|c|c|c|c|c|}
\hline Specimen & Cycles & Depth $(\mathrm{mm})$ & $f_{\mathrm{CC}, i}^{d}(\mathrm{Mpa})$ & $\varepsilon_{c 0, i}$ & $\varepsilon_{c c u, i}$ & $E_{c, i}^{d}$ \\
\hline $\mathrm{Z}-\mathrm{C1}$ & 0 & 20-100 & 46.41 & 0.0038 & 0.02 & 32973.5 \\
\hline $\mathrm{Z}-\mathrm{C} 2$ & 100 & $20-100$ & 46.41 & 0.0038 & 0.02 & 32973.5 \\
\hline \multirow{3}{*}{$\mathrm{Z}-\mathrm{C} 3$} & \multirow{3}{*}{200} & $20-30$ & 38.74 & 0.0046 & 0.02 & 22954.6 \\
\hline & & $30-40$ & 43.31 & 0.0045 & 0.02 & 26023.8 \\
\hline & & $40-100$ & 46.41 & 0.0038 & 0.02 & 32973.5 \\
\hline \multirow{7}{*}{$\mathrm{Z}-\mathrm{C} 4$} & \multirow{7}{*}{300} & $20-30$ & 26.43 & 0.0065 & 0.02 & 11131.0 \\
\hline & & $30-40$ & 30.10 & 0.0055 & 0.02 & 15060.1 \\
\hline & & $40-50$ & 33.60 & 0.0049 & 0.02 & 18561.9 \\
\hline & & $50-60$ & 37.07 & 0.0047 & 0.02 & 21636.4 \\
\hline & & $60-70$ & 40.59 & 0.0046 & 0.02 & 24283.5 \\
\hline & & $70-80$ & 44.14 & 0.0045 & 0.02 & 26503.3 \\
\hline & & $80-100$ & 46.41 & 0.0038 & 0.02 & 32973.5 \\
\hline
\end{tabular}

4.4. Validation of Proposed Model. Four RC columns subjected to FTCs with 0 cycles, 100 cycles, 200 cycles, and 300 cycles were simulated, respectively, by using the abovementioned models considering the uneven distribution of frozen-thawed damage. The most important input parameters for frozen-thawed unconfined and confined concrete with $d$ were listed in Tables 5 and 6 . The comparison between tests and simulations for hysteretic response is shown in Figure 14. It can be seen that the simulation results of frozen columns with 100 cycles, 200 cycles, and 300 cycles are in good agreement with the experiment. However, the proposed model did not consider the bond-slip phenomenon between longitudinal steel bars and freeze-thawed concrete; thus the strength degradation after peak point was inconsistent with the tests, so it is necessary to establish the bond-slip constitutive relations for frozen-thawed concrete with steel bars in the future research. As for the test result of intact column with 0 FTCs, the positive bearing capacity was larger than the negative one due to the test error with misalignment of the centerlines for hydraulic jack and column before the cyclic loading imposed. When the column with 0 FTCs was simulated, this misalignment above was not considered; therefore, the simulative positive bearing capacity was lower than the experimental value; on the contrary, the simulative negative initial stiffness and negative bearing capacity were larger than experimental values. To sum up, the proposed model in this paper has a good applicability, which can simulate the freezing-thawing process of $\mathrm{RC}$ members reasonably, and has better accuracy than that simulated by using conventional methods assuming even distribution of frozenthawed damage.

\section{Conclusions}

An experimental study was undertaken to investigate the influence of FTCs on the seismic behavior of RC columns. The effects of the numbers of FTCs on the failure modes, hysteretic response, and skeleton curves of the specimens were analysed. Meanwhile, a methodology considering uneven distribution of frozen-thawed damage to analyse the hysteretic behavior of frozen-thawed RC columns was introduced. The results of the simulation were compared with the above experiments for RC columns. The following conclusions can be drawn based on this study:

(1) FTCs did not change the destruction form of RC columns and all specimens experienced typically bending-shear failures mainly dominated by flexure. In addition, the degree of granulation reduced gradually from the outer to the inner part of columns, which revealed the uneven distribution of freezing-thawing damage.

(2) The hysteretic characteristics of specimens subjected to different number of FTCs are similar. With the 


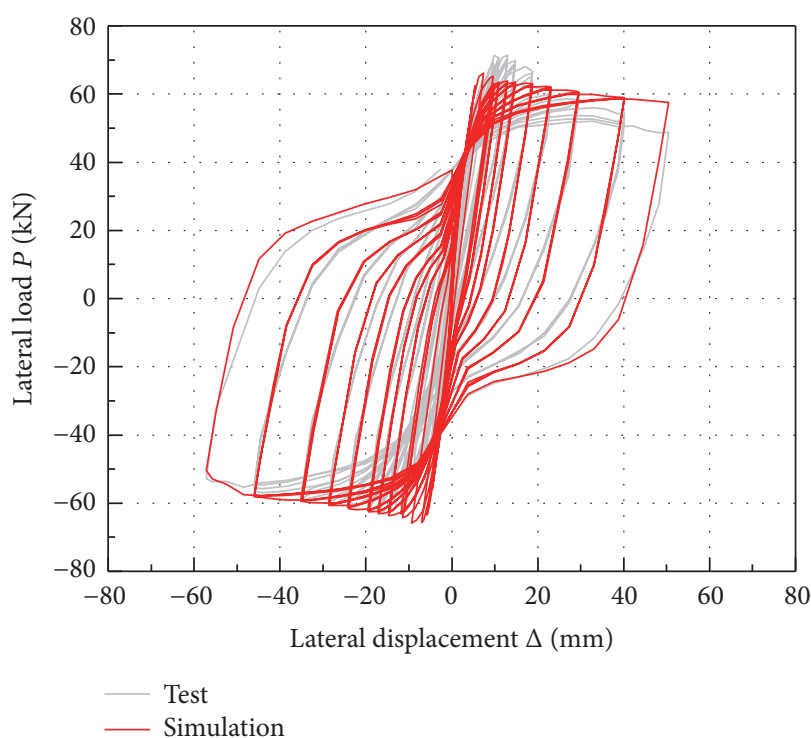

(a) Z-C1 (0 cycles)

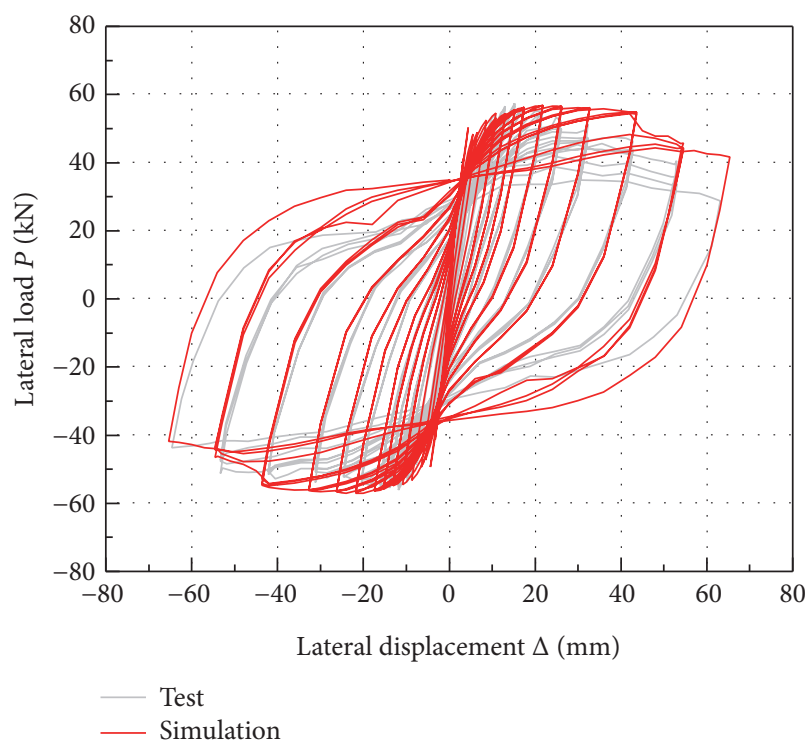

(c) Z-C3 (200 cycles)

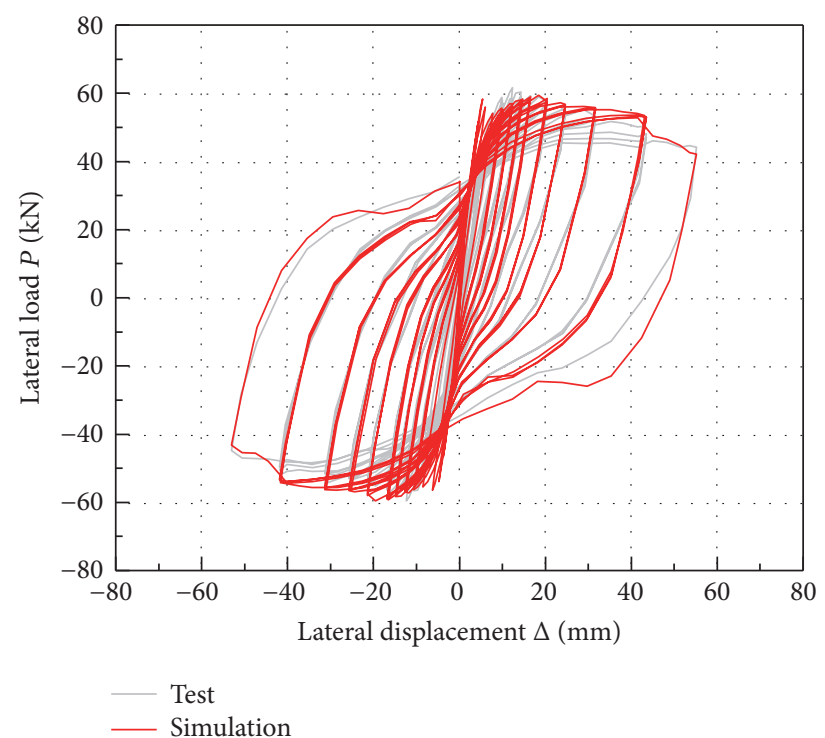

(b) Z-C2 (100 cycles)

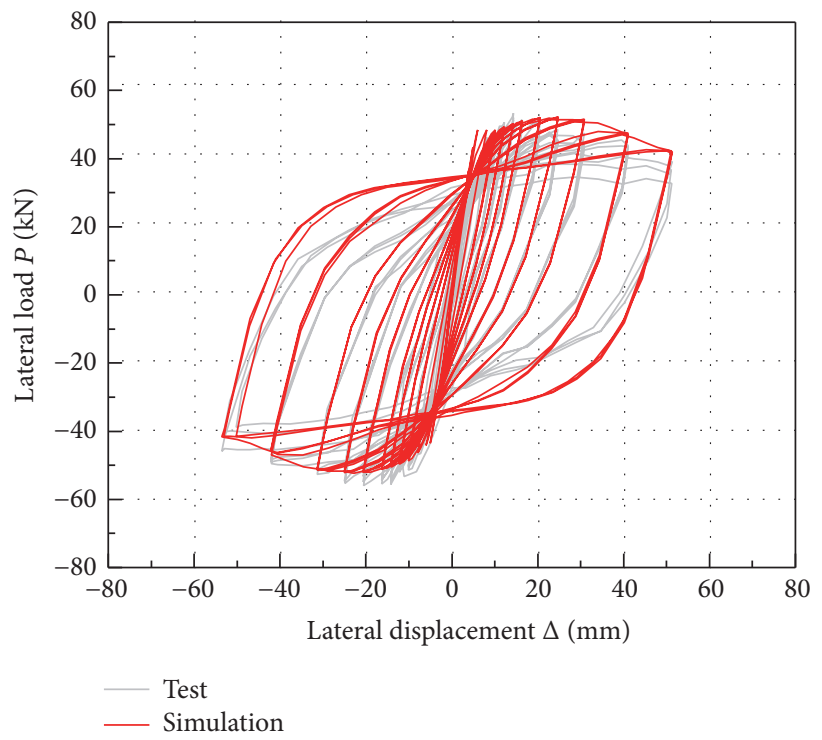

(d) Z-C4 (300 cycles)

FIGURE 14: Comparison between hysteretic responses of experiment and modeling.

increase of freeze-thaw cycles, the bearing capacity of specimens decreased gradually; however the displacements for different damage states increased slightly, and the corresponding ductility factors declined gradually.

(3) The numbers of FTCs with different freeze-thaw conditions could be transformed mutually by utilizing Berto's method. As a result, the 100 cycles, 200 cycles, and 300 cycles of freeze-thaw tests in this paper were equivalent to 50 cycles, 130 cycles, and 229 cycles, respectively, under the ASTM C666 proc. A condition and were equivalent to 13 cycles, 40 cycles, and 76 cycles under the RILEM TC176-IDC condition.
(4) The calculation model of RDME considering the uneven freeze-thaw damage was proposed by linear regression analysis for Petersen's test data based on some assumptions. And then the compressive strength of frozen-thawed confined/unconfined concrete and the corresponding static modulus of elasticity with various freeze-thaw depths were calculated. On the basis of the existing constitutive relations for concrete, the simulation hysteretic curves calculated by OpenSees were in good agreement with the experimental ones.

The proposed methodology did not consider the bondslip phenomenon between longitudinal steel bars and 
freeze-thawed concrete; it is necessary to establish the bondslip constitutive relations in future research.

\section{Competing Interests}

The authors declare that they have no competing interests.

\section{Acknowledgments}

This study was supported by the National Key Technology R\&D Program under Grant no. 2013BAJ08B00, the Natural Science Foundation of China under Grant nos. 50978218 and 51108376, and the Natural Science Foundation of Shaanxi Provincial Department of Education under Grant nos. 2016KJXX-93 and 2014JQ7231.

\section{References}

[1] A. Duan, W. L. Jin, and J. R. Qian, "Effect of freeze-thaw cycles on the stress-strain curves of unconfined and confined concrete," Materials and Structures, vol. 44, no. 7, pp. 1309-1324, 2011.

[2] L. Petersen, L. Lohaus, and M. A. Polak, "Influence of freezingand-thawing damage on behavior of reinforced concrete elements," ACI Materials Journal, vol. 104, no. 4, pp. 369-378, 2007.

[3] K. Z. Hanjari, P. Utgenannt, and K. Lundgren, "Experimental study of the material and bond properties of frost-damaged concrete," Cement and Concrete Research, vol. 41, no. 3, pp. 244254, 2011.

[4] M. Hasan, H. Okuyama, Y. Sato, and T. Ueda, "Stress-strain model of concrete damaged by freezing and thawing cycles," Journal of Advanced Concrete Technology, vol. 2, no. 1, pp. 8999, 2004.

[5] H. S. Shang and Y. P. Song, "Experimental study of strength and deformation of plain concrete under biaxial compression after freezing and thawing cycles," Cement and Concrete Research, vol. 36, no. 10, pp. 1857-1864, 2006.

[6] S. Xu, A. Li, Z. Ji, and Y. Wang, "Seismic performance of reinforced concrete columns after freeze-thaw cycles," Construction and Building Materials, vol. 102, pp. 861-871, 2016.

[7] W. Yang, S.-S. Zheng, D.-Y. Zhang, L.-F. Sun, and C.-L. Gan, "Seismic behaviors of squat reinforced concrete shear walls under freeze-thaw cycles: a pilot experimental study," Engineering Structures, vol. 124, pp. 49-63, 2016.

[8] T. Ueda, M. Hasan, K. Nagai, Y. Sato, and L. Wang, "Mesoscale simulation of influence of frost damage on mechanical properties of concrete," Journal of Materials in Civil Engineering, vol. 21, no. 6, pp. 244-252, 2009.

[9] K. Z. Hanjari, P. Kettil, and K. Lundgren, "Modelling the structural behaviour of frost-damaged reinforced concrete structures," Structure and Infrastructure Engineering, vol. 9, no. 5, pp. 416-431, 2013.

[10] H. Hayashida, Y. Sato, and T. Ueda, "Evaluation of structural properties of the freeze-thaw-damaged RC beam members by nonlinear finite-element analysis," in Proceedings of the 4th International Conference on the Durability of Concrete Structures (ICDCS '14), pp. 45-51, Purdue University, West Lafayette, Ind, USA, July 2014.

[11] L. Berto, A. Saetta, D. A. Talledo, and R. Vitaliani, "Structural analysis of frost damaged constructions by means of a coupled environmental-mechanical damage model," in Proceedings of the Joint 11th World Congress on Computational Mechanics (WCCM '14), pp. 904-915, Barcelona, Spain, July 2014.

[12] L. Berto, A. Saetta, R. Scotta, and D. Talledo, "A coupled damage model for RC structures: proposal for a frost deterioration model and enhancement of mixed tension domain," Construction and Building Materials, vol. 65, pp. 310-320, 2014.

[13] L. Berto, A. Saetta, and D. Talledo, "Constitutive model of concrete damaged by freeze-thaw action for evaluation of structural performance of RC elements," Construction and Building Materials, vol. 98, pp. 559-569, 2015.

[14] GB 50011-2010, "Code for seismic design of buildings," China Architecture and Building Press, Beijing, China, 2010.

[15] GB, "Standard for test method of concrete structures," GB/T 50152-2012, Chinese Standards, Beijing, China, 2012.

[16] Chinese Standard, Standard for Test Methods of Long-term Performance and Durability of Ordinary Concrete (GB/T500822009), China Architecture and Building Press, Beijing, China, 2009.

[17] R. Park, "Evaluation of ductility of structures and structural assemblages from laboratory testing," Bulletin of the New Zealand National Society for Earthquake Engineering, vol. 22, no. 3, pp. 155-166, 1989.

[18] C. K. Gulec and A. S. Whittaker, "Performance-based assessment and design of squat reinforced concrete shear walls," MCEER-09-0010, 2009.

[19] V. Terzic, J. Matthew, I. Jose, and A. Stephen, "Concrete Column Blind Prediction Contest 2010: Outcomes and Observations," PEER Report, 2015.

[20] M. Menegotto and P. E. Pinto, "Method of analysis for cyclically loaded reinforced concrete plane frames including changes in geometry and non-elastic behavior of elements under combined normal force and bending," Preliminary Report IABSE, vol. 13, 1973.

[21] F. C. Filippou, E. P. Popov, and V. V. Bertero, "Effects of bond deterioration on hysteretic behavior of reinforced concrete joints," Report EERC 83-19, Earthquake Engineering Research Center, University of California, Berkeley, Calif, USA, 1983.

[22] M. Hisham and M. Yassin, Nonlinear analysis of prestressed concrete structures under monotonic and cycling loads [Ph.D. dissertation], University of California, Berkeley, Calif, USA, 1994.

[23] J. B. Mander, M. J. Priestley, and R. Park, “Theoretical stressstrain model for confined concrete," Journal of Structural Engineering, vol. 114, no. 8, pp. 1804-1826, 1988.

[24] I. D. Karsan and J. O. Jirsa, "Behavior of concrete under compressive loading," Journal of Structural Division ASCE, vol. 95, no. ST12, 1969.

[25] H. E. H. Roy and M. A. Sozen, "Ductility of concrete," in Flexural Mechanics of Reinforced Concrete, ACI Special Publication SPI2, pp. 213-235, ACI, Miami, Fla, USA, 1964.

[26] American Standard ASTM C666, "Standard test method for resistance of concrete to rapid freezing and thawing," 2008.

[27] M. J. Setzer, P. Heine, S. Kasparek et al., "Test methods of frost resistance of concrete: GIF-Test: capillary suction, internal damage and freeze thaw test-reference method and alternative methods A and B," Materials and Structures, vol. 37, no. 274, pp. 743-753, 2004.

[28] CP110, "Code of practice for the structural use of concrete," British Standards Institution, London, UK, 1972. 

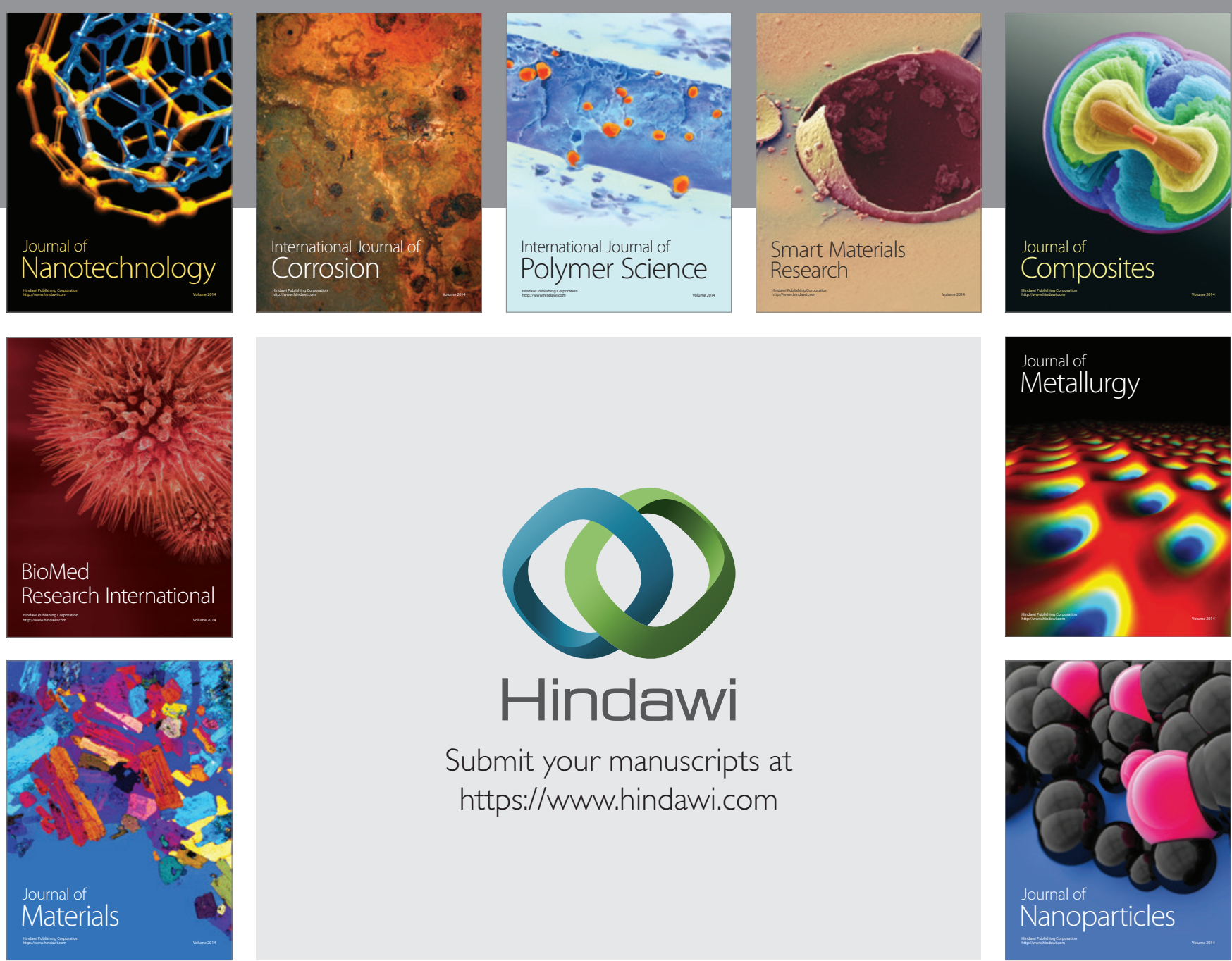

\section{Hindawi}

Submit your manuscripts at

https://www.hindawi.com

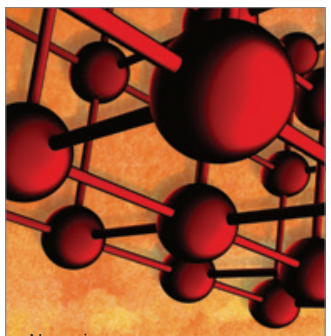

Materials Science and Engineering
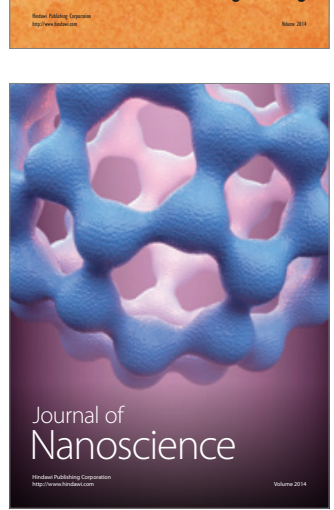
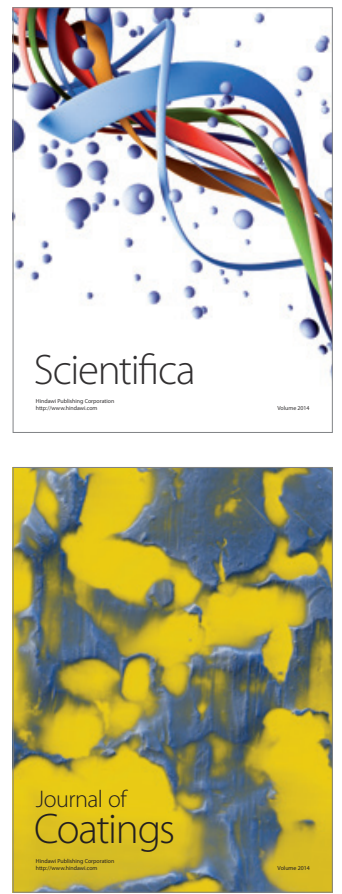
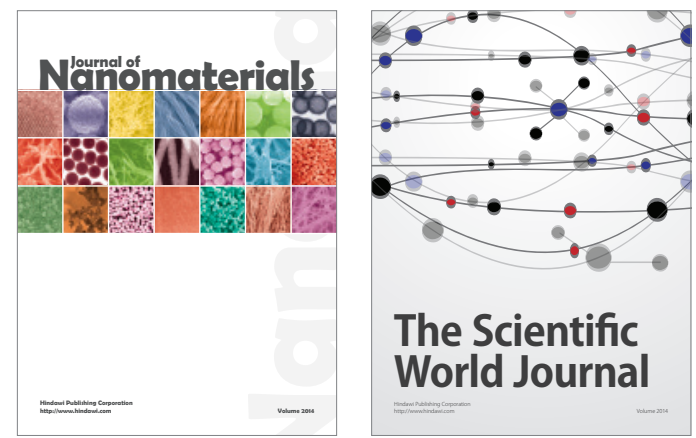

The Scientific World Journal
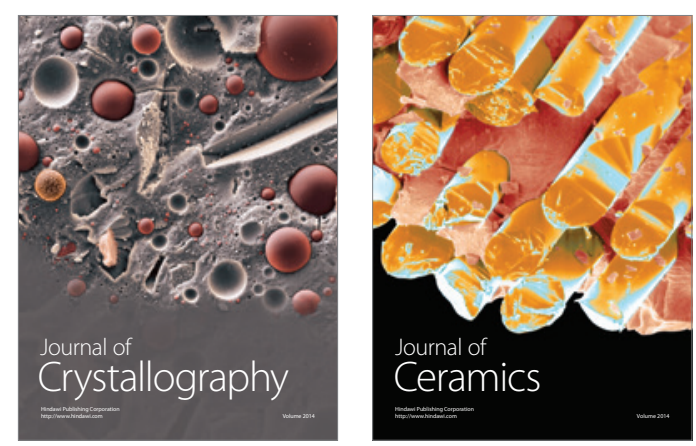
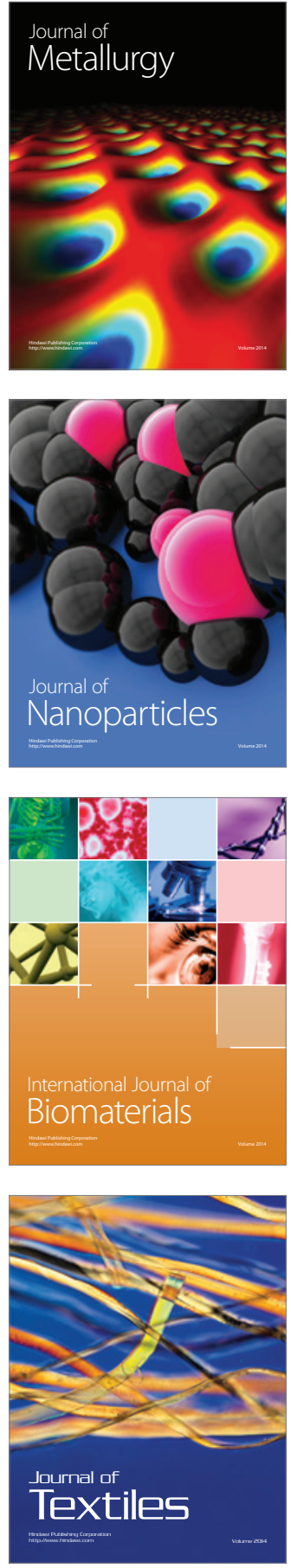